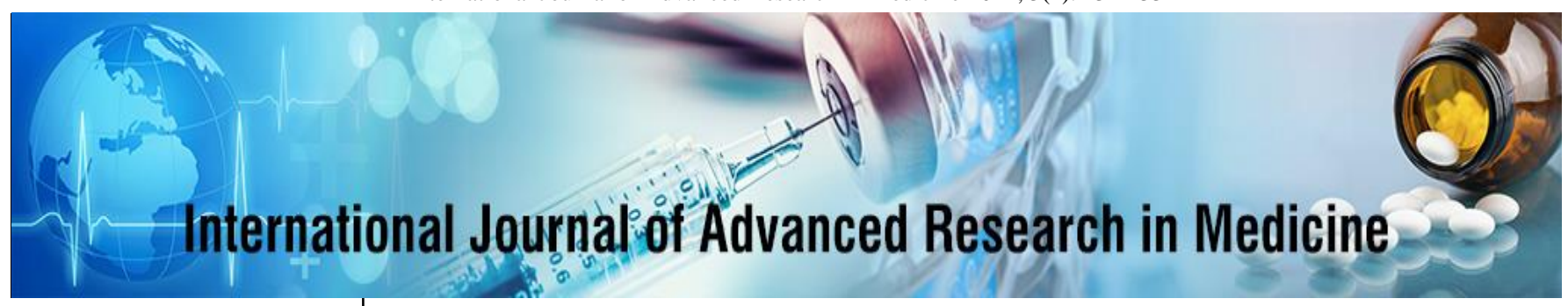

E-ISSN: 2706-9575

P-ISSN: 2706-9567

IJARM 2021; 3(1): 131-133

Received: 01-11-2020

Accepted: 07-12-2020

Dr. Sadanand Naik

Assistant Professor,

Department of General

Medicine, Srinivas Institute of

Medical Sciences, Mangalore,

Karnataka, India

Dr. Sundara Anemajal

Assistant Professor,

Department of General

Medicine, Srinivas Institute of

Medical Sciences, Mangalore,

Karnataka, India
Corresponding Author: Dr. Sundara Anemajal Assistant Professor,

Department of General Medicine, Srinivas Institute of Medical Sciences, Mangalore, Karnataka, India

\section{A study of asymptomatic bacteriuria in patients with diabetes mellitus}

\author{
Dr. Sadanand Naik and Dr. Sundara Anemajal
}

DOI: $\underline{\text { https://doi.org/10.22271/27069567.2021.v3.i1c.113 }}$

\begin{abstract}
Diabetes is very common predisposing factor for UTI. The fact that asymptomatic bacteriuria is more common in females with diabetes as compared to males with diabetes. Asymptomatic bacteriuria (ASB) is defined as When a bacterial count of same species over $10^{\wedge} 5$ per $\mathrm{ml}$ in mild stream clean catch specimen of urine on two occasion is detected without the symptom of urinary infection. Significant bacteriuria detected by urinary culture, without symptoms attributable to urinary tract like burning micturition, frequent micturition, urinary incontinence, urgency, painful micturition, suprapubic pain, flank pain or fever. Asymptomatic and symptomatic bacteriuria are more common in females with diabetes. Asymptomatic bacteriuria may be precursor for symptomatic bacteriuria. The UTI ranges from asymptomatic bacteriuria to lower cystitis, pyelonephritis, xanthogranulomatous pyelonephritis, renal abscess, perinephric abscess, and papillary necrosis. Asymptomatic bacteriuria seems to be non eradicable, recurring in case of diabetic females.
\end{abstract}

Keywords: Asymptomatic, Bacteriuria, diabetes mellitus

\section{Introduction}

Diabetes Mellitus popularly known as sugar problem among the people of India. It is a chronic, non-communicable, widespread, multiorgan disease. The diseases affects the pancreas insulin activity leading to raised blood glucose level. The insulin is either reduced or inactive. The population affected by diabetes is increasing due to population growth, aging, urbanization, obesity and physical inactivity. The prevalence of disease will increase worldwide from 171 million in 2000 to 366 million in $2030^{[1]}$. It is a multiorgan dysfunction disease. People affected with diabetes mellitus have significant chances of getting urinary tract infections as compared to non diabetic persons ${ }^{[2]}$. And it has also been stated that diabetic people suffer from more complications compared to non diabetics. Common infections in diabetic patients includes respiratory infections, urinary infections, ear infections, soft tissue infections and abdominal problems. Diabetes mellitus has a range of effects on various organ systems ${ }^{[3]}$ a 1940 autopsy study showed that $18 \%$ of the subjects with diabetes had a urinary tract infection (UTI) ${ }^{[2]}$. Also diabetic patients are prone to asymptomatic UTI ${ }^{[4]}$. The spectrum of UTI in these patients ranges from asymptomatic bacteriuria (ASB) to lower UTI (cystitis), pyelonephritis, and severe urosepsis. Serious complications of UTI, such as emphysematous cystitis and pyelonephritis, renal abscesses and renal papillary necrosis, are all encountered more frequently in type 2 diabetes than in the general population ${ }^{[5,7]}$. Type 2 diabetes is not only a risk factor for community-acquired UTI but also for health care-associated UTI ${ }^{[8]}$, catheter-associated UTI ${ }^{[9]}$ and post-renal transplant-recurrent UTI In addition, these patients are more prone to have resistant pathogens as the cause of their UTI, including extended-spectrum $\beta$-lactamase-positive Enterobacteriaceae, fluoroquinolone-resistant uropathogens, carbapenem-resistant Enterobacteriaceae, and vancomycin-resistant Enterococci. Type 2 diabetes is also a risk factor for fungal UTI, mostly caused by Candida. 21 Diabetes is also associated with worse outcomes of UTI, including longer hospitalizations and increased mortality.

\section{Aims and Objectives}

To the outcomes of asymptomatic bacteriuria in patients with diabetes mellitus. 


\section{Materials and Methods}

This study was done in the Department of General Medicine, Srinivas Institute of Medical Sciences, Mangalore.

The study was done from April 2017 to April 2019

The patients sample size was 100 .

\section{Inclusion Criteria}

- The history of the patients should include a follow up sheet at $3^{\text {rd }}$ and $6^{\text {th }}$ month.

- Culture showed positive history in records

\section{Exclusion criteria}

- Patients on immunodeficiency, steroid therapy or immune modulator drugs.

- Without complete follow up history.

\section{Results}

Table 1: Mean age of the Subjects

\begin{tabular}{|c|c|}
\hline Mean Age & Std deviation \\
\hline $61 \pm 38$ years & \pm 16.27 years \\
\hline
\end{tabular}

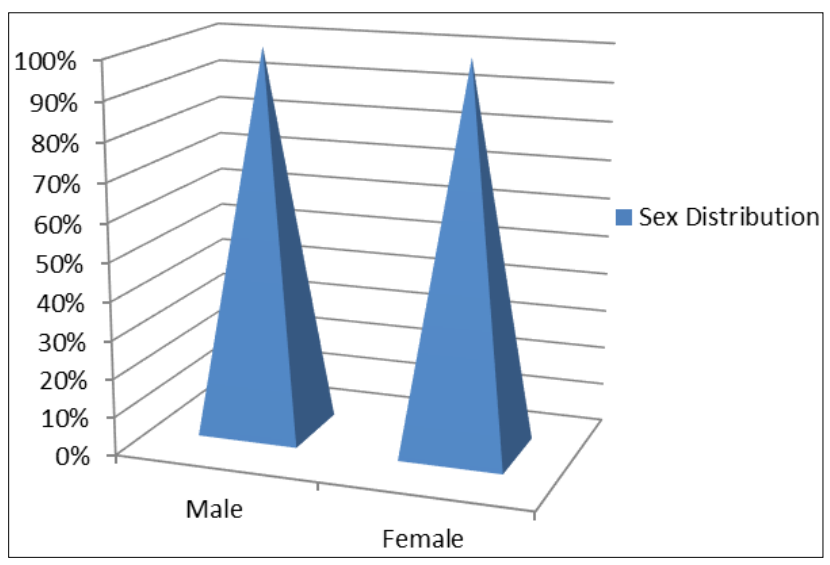

Fig 1: Sex Distribution

Table 2: Outcomes: At 3 months

\begin{tabular}{|c|c|}
\hline Symptomatic UTI & $\mathbf{4}$ \\
\hline Hypertension & 1 \\
\hline HbA1C & $8.7 \pm 0.6$ \\
\hline Macroalbuminuria & 2 \\
\hline Microalbuminuria & 1 \\
\hline eGFR (ml/min/1.732) & $92.4 \pm 13.47$ \\
\hline
\end{tabular}

Table 3: Outcomes: At 6 months

\begin{tabular}{|c|c|}
\hline Symptomatic UTI & $\mathbf{0 9}$ \\
\hline Hypertension & 06 \\
\hline HbA1C & $8.2 \pm 1.1$ \\
\hline Macroalbuminuria & 1 \\
\hline Microalbuminuria & 2 \\
\hline eGFR $\left(\mathrm{ml} / \mathrm{min} / 1.73^{2}\right)$ & $91.74 \pm 07.02$ \\
\hline
\end{tabular}

\section{Discussion}

All types of UTI are more frequent in patients with type 2 diabetes. Various studies have reported the overall incidence of UTI among these patients. An observational study of all patients with type 2 diabetes in the UK general practice research database found that the incidence rate of UTI was 46.9 per 1,000 person-years among diabetic patients and 29.9 for patients without diabetes. Women with previously diagnosed diabetes had a higher risk of UTI than those with recently diagnosed diabetes (within 6 months) $(91.9 / 1,000$ person-years; 95\% confidence interval [CI] 84.3-99.4, vs 70.5/1,000 person-years; 95\% CI 68.2-72.8).24 A cohort study of over 6,000 patients enrolled in ten clinical trials found an incidence rate of 91.5 per 1,000 person-years in women and 28 per 1,000 person-years in men, and a cumulative incidence of $2 \%$ during 6 months. A recent American study performed on a health service data base with more than 70,000 patients with type 2 diabetes found that $8.2 \%$ were diagnosed with UTI during 1 year $(12.9 \%$ of women and $3.9 \%$ of men, with incidence increasing with age). Another American database study from 2014 found that a UTI diagnosis was more common in men and women with diabetes than in those without diabetes $(9.4 \%$ vs $5.7 \%$, respectively) among 89,790 matched pairs of patients with and without type 2 diabetes mellitus.

ASB is more prevalent in women, due to a short urethra that is in proximity to the warm, moist, vulvar, and perianal areas that are colonized with enteric bacteria. ASB increases with age, and is also associated with urinary tract abnormalities or foreign bodies (urethral catheters, stents, etc). Many studies have reported an increased prevalence of ASB in diabetic patients, with estimates ranging from $8 \%-$ $26 \%$. A meta- analysis of 22 studies, published in 2011, found a point prevalence of $12.2 \%$ of ASB among diabetic patients versus $4.5 \%$ in healthy control subjects.31 The point prevalence of ASB was higher both in women and men, was higher in patients with a longer duration of diabetes, and was not associated with glycemic status, as evaluated by glycosylated hemoglobin $A_{1 c}\left(H b A_{1 c}\right)$. A recent prospective study of inpatients at an Indian hospital found a $30 \%$ prevalence rate of ASB among diabetic patients.

\section{Conclusion}

This study was successful to study the outcomes of asymptomatic bacteriuria in patients with diabetes mellitus. This would be a boon to the practising physicians and is intended to help the budding general practitioners.

\section{References}

1. Wild S, Bchir M, Roglic G, Green A, Sicree R, King H. Global Prevalence of Diabetes. Diabetes Care 2004;27(5):7.

2. Geerlings SE, Stolk RP, Camps MJL, Netten PM, Hoekstra JBL, Bouter KP et al. Asymptomatic Bacteriuria May Be Considered a Complication in Women With Diabetes. Diabetes care 2000;23(6):6.

3. Joshi N, Caputo GM, Weitekamp MR, Karchmer AW. Infections in Patients with Diabetes Mellitus. N Engl J Med 1999;341(25):1906-12.

4. Singh A, Godara S, Jeswani JA. Original Research Article 2019;6(19):6.

5. Bonadio M, Boldrini E, Forotti G, Matteucci E, Vigna A, Mori $\mathrm{S}$ et al. Asymptomatic Bacteriuria in Women with Diabetes: Influence of Metabolic Control 5.

6. Geerlings SE, Stolk RP, Camps MJL, Netten PM, Hoekstra JBL, Bouter PK et al. Asymptomatic Bacteriuria can be Considered a Diabetic Complication in Women with Diabetes Mellitus. In: Emoődy L, Pál T, Hacker J, Blum-Oehler G, editors. Genes and Proteins Underlying Microbial Urinary Tract Virulence [Internet]. Boston, MA: Springer US; 2002 [cited 2021 
Jan 14]. p. 309-14. (Back N, Cohen IR, Kritchevsky D, Lajtha A, Paoletti R, editors. Advances in Experimental Medicine and Biology; vol. 485). Available from: http://link.springer.com/10.1007/0-306-46840-9_41

7. Nitzan O, Elias M, Chazan B, Saliba W. Urinary tract infections in patients with type 2 diabetes mellitus: review of prevalence, diagnosis, and management 8 .

8. Nicolle LE, Zhanel GG, Harding GKM. Microbiological outcomes in women with diabetes and untreated asymptomatic bacteriuria. World J Urol 2006;24(1):61-5.

9. Valerius NH, Eff C, Hansen NE, Karle H, Nerup J, Søeberg B et al. Neutrophil and Lymphocyte Function in Patients with Diabetes Mellitus. Acta Medica Scandinavica 2009;211(6):463-7.

10. Vejlsgaard R. Studies on urinary infection in diabetics. II Significant bacteriuria in relation to long-term diabetic manifestations. Acta Med. Scand 1966;179:183-188.

11. Delamaire M, Maugendre D, Moreno M, Goff M-CL, Allannic H, Genetet B. Impaired Leucocyte Functions in Diabetic Patients 6. 